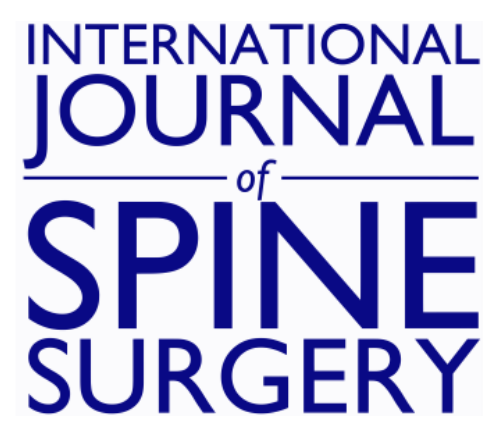

\title{
Fractures of C2 (Axis) Vertebra: Clinical Presentation and Management
}

AHMED BAKHSH, AHMED ALZAHRANI, ALI HASSAN ALJUZAIR, UMAIR AHMED and HANY ELDAWOODY

Int J Spine Surg 2020, 14 (6) 908-915

doi: https://doi.org/10.14444/7139

http://ijssurgery.com/content/14/6/908

This information is current as of April 25, 2023.

Email Alerts Receive free email-alerts when new articles cite this article. Sign up at:

http://ijssurgery.com/alerts

The International Journal of Spine Surgery

2397 Waterbury Circle, Suite 1,

Aurora, IL 60504, Phone: +1-630-375-1432 


\title{
Fractures of C2 (Axis) Vertebra: Clinical Presentation and Management
}

\author{
AHMED BAKHSH, MBBS, MS, ${ }^{1}$ AHMED ALZAHRANI, MD ${ }^{2}$ ALI HASSAN ALJUZAIR, MBBS SB- \\ Neurosurg (Ottawa), ${ }^{3}$ UMAIR AHMED,${ }^{4}$ HANY ELDAWOODY, MD, PHD ${ }^{5}$ \\ ${ }^{1}$ Prince Mohammed Bin Abdulaziz Hospital, Riyadh, Kingdom of Saudi Arabia, ${ }^{2}$ Security Forces Hospital, Riyadh, Kingdom of Saudi Arabia, ${ }^{3}$ Prince Mohammed \\ Bin Abdulaziz Hospital, Riyadh, Kingdom of Saudi Arabia, ${ }^{4}$ Wah Medical College, Wah, Pakistan, ${ }^{5}$ Department of Neurosurgery, Mansoura Faculty of Medicine, \\ Mansoura University, Egypt, and Prince Mohammed Bin Abdulaziz Hospital, Riyadh, Kingdom of Saudi Arabia
}

\begin{abstract}
Background: Injuries of the upper cervical spine are a major cause of morbidity and mortality due to associated spinal cord and head injuries. The injury patterns of the upper cervical spine are numerous, and the neurologic sequelae are diverse. The axis (C2) is the most commonly fractured vertebra in the upper cervical spine; its unique anatomy and architecture pose difficulties in the diagnosis and the management of its fractures.

Methods: All cases of acute spinal injuries at Prince Mohammed Bin Abdulaziz Hospital in Riyadh, Saudi Arabia, were screened for fractures of $\mathrm{C} 2$ vertebrae. These patients underwent computerized tomography (CT) imaging of the cervical spine with special attention paid to the cranio-cervical junction. Magnetic resonance imaging (MRI) and angiography of the neck were performed to exclude ligamentous tears and vascular injuries. Unstable fractures were fixed surgically. In the remaining cases, a conservative trial was given. All patients were followed up once every 3 months for a period of 1 year. During follow-up, some patients underwent additional CT imaging of the cervical spine to monitor the healing of fractures.

Results: Out of 230 spinal trauma patients, $43.5 \%$ suffered from cervical spine injury. C2 fractures were recorded in $26 \%$ cases, and fractures of the $\mathrm{C} 2$ vertebral body, including pedicles, laminae, lateral masses, and articular processes, were found in many cases, followed by odontoid fractures $(50 \%)$. No case of atlanto-axial or atlanto-occipital dislocation was recorded. Road traffic accidents were found to be responsible for $92 \%$ of cases. The majority of patients were young males, and $96 \%$ of patients had no neurological deficit. Only $15 \%$ of the patients required surgery for their unstable fractures. Half of the patients attended outpatient follow -up appointments, all of whom underwent CT scanning of the cervical spine 9 months after the accident or operation.

Conclusions: The axis (C2) is the most commonly affected vertebra in cervical spine trauma, and odontoid fractures make up $50 \%$ of all C2 fractures. C2 fractures rarely cause any neurological deficit or vascular injury, and the majority of affected patients can be managed conservatively; only a small proportion requires surgical intervention. Surgical intervention leads to early and complete healing.
\end{abstract}

Cervical Spine

Keywords: cervical spine, fractures, axis, odontoid process, nonhealing

\section{BACKGROUND}

It is essential to be familiar with the complex anatomy and kinematics of the upper cervical spine. It is composed of occipital condyles, the atlas, and the axis along with atlanto-occipital and atlantoaxial joints. The apical, alar, and cruciate ligaments constrain the movements of the atlanto-axial articulation. Other ligaments supporting the cervical spine are anterior and posterior longitudinal ligaments along with the posterior ligament complex. . $^{1,2}$ The $\mathrm{C} 1-\mathrm{C} 2$ complex allows $50 \%$ of all the rotation of the entire spine and $10^{\circ}$ of flexion-extension and 50 degrees of axial rotation. Therefore, the fusion of these segments would undoubtedly cause this motion to be permanently lost. ${ }^{3}$

There is no universally accepted classification system for upper cervical injuries, such as the Subaxial Injury Classification System) and the Thoracolumbar Injury Classification System. ${ }^{4}$ Occipital condyle fractures are classified by Anderson and Montesano. Atlas fractures are classified into type I (posterior arch fractures), type II (anterior arch fractures), type III (Jefferson fracture), type IV (lateral mass fractures), and type $\mathrm{V}$ (transverse fractures of the anterior arch). Anderson and D'Alonzo classified odontoid fractures into 3 types. Type 2 odontoid fractures are further classified by 
Apfelbaum into 3 subtypes, depending on the direction of the fracture line: type $2 \mathrm{a}$, where the line is anterior oblique; type $2 \mathrm{~b}$, where the line is posterior oblique; and type 2c, where the line is horizontal. Hangman's fractures (axis ring fractures) are classified by Effendi et al and modified by Levine and Edwards. ${ }^{5}$ A locked $\mathrm{C} 2-\mathrm{C} 3$ facet joint constitutes a type III lesion in both classification systems. The Traynelis classification divides atlanto-occipital dislocations into 3 types. Horn et al propose another classification in which grade I lesions have moderately abnormal findings on MRI and grade II lesions have grossly abnormal findings on MRI. ${ }^{6}$ Fielding and Hawkins classify rotatory atlanto-axial instability into four types: (1) rotatory subluxation without any anteroposterior translation, (2) rotatory subluxation with an anterior shift of 3-5 mm, (3) rotatory subluxation with an anterior shift of $>5 \mathrm{~mm}$, and (4) rotatory subluxation with a posterior shift. ${ }^{7,8}$ Lesions of the transverse atlanto-axial ligament are classified according to De La Caffinière et al. ${ }^{9,10}$ These different types of classification systems clearly show how complex this area is and how difficult it is to agree on a unanimous and unified universal classification system for this area. This is why controversies exist regarding the true management of different types of fractures in this complex area.

Fractures of the second cervical vertebrae are commonly seen in spine surgery. These fractures account for approximately one-third of all cervical spine fractures. The etiology for these fractures is either high-energy mechanisms in younger patients or low-energy trauma in the older population. ${ }^{11}$ Odontoid fractures are the most common subset in $\mathrm{C} 2$ vertebral injury. Their main issue is nonunion and delayed myelopathy. There are also no treatment guidelines available for odontoid fractures. For type I and type III fractures, immobilization yields the best results in many cases. For type II fractures, halo vest immobilization and posterior fixation provide similar fusion rates. Anterior fixation appears to increase the fusion rate. Nevertheless, the optimum treatment strategy is still debated and controversial. ${ }^{12}$

In this study, we shall examine the frequency of C2 fractures, their subtypes, and their management in cervical spine injuries

\section{METHODS}

All patients with an acute spinal injury with or without polytrauma admitted at Prince Mohammed
Bin Abdulaziz Hospital in Riyadh, Saudi Arabia. between January 2017 and June 2018 were screened for second cervical (axis) fractures. Patients with chronic spinal injury, operated spinal injury, firearm injuries, or autoimmune and congenital bone diseases were excluded from the study.

In the emergency department, all cases were managed according to advanced trauma life support protocols. All patients had a whole-body computerized tomography (CT) scan including the cervical spine. In those who had positive CT findings or were symptomatic with normal CT scans, magnetic resonance imaging (MRI) was performed to rule out any ligamentous tears and vascular injury. CT/ MRI angiography of the neck was performed in selected cases where there was a strong suspicion of vascular injury. The severity of spinal cord injury was quantified using the American Spinal Injury Association grades.

In all cases, the neck was immobilized with the hard cervical collar. In polytrauma cases, patients were first stabilized and cleared by the trauma surgery teams. Patients with unstable fractures underwent elective surgery in the form of odontoid screw insertion or anterior/posterior $\mathrm{C} 1-\mathrm{C} 2$ fusion and fixation. Patients who did not require surgery were managed conservatively in the form of a neck collar and pain medication. CT scans of the neck were performed to check the spine alignment and implant position in all operated cases. All patients were discharged home with a Philadelphia collar and advised to attend for the regular follow-up. CT imaging of the cervical spine was repeated 9 months later in follow-up cases to observe for evidence of fusion/healing.

\section{RESULTS}

In total, 230 cases of spinal trauma were assessed in the emergency department during a period of a year and a half. One hundred patients suffered from a cervical spine injury. Twenty-six patients had C2 fractures either isolated or associated with $\mathrm{C} 1$ and C3 fractures (Figures 1-6). Fifty percent were odontoid fractures (Table 1). Ninety-six percent of patients were male, and $73 \%$ of patients were less than 50 years old (Table 2). Road traffic accidents were responsible for the injury in $92 \%$ of cases. One-third of patients had polytrauma involving chest, abdomen, and long bone injuries. Ninety-six percent of patients remained neurologically intact. One patient was paraplegic due to his concomitant 


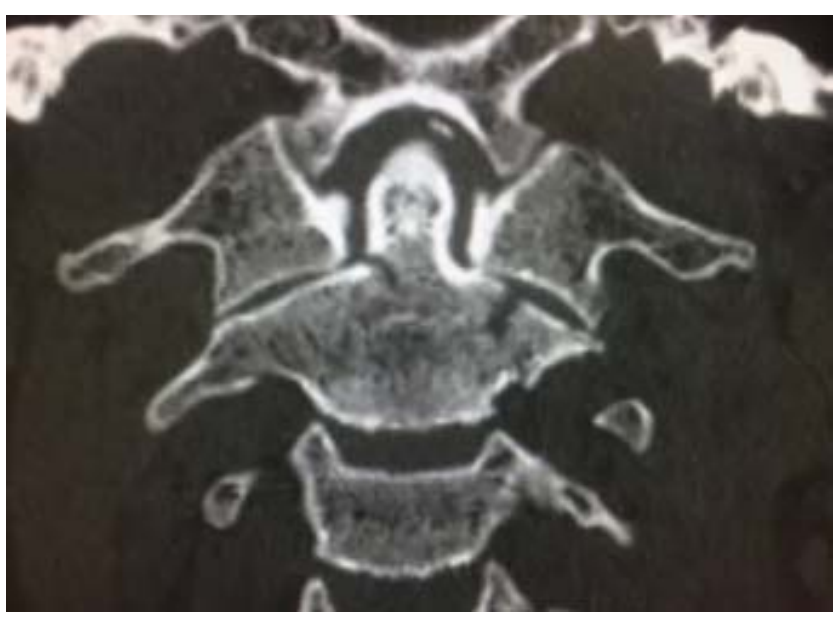

Figure 1. Type 3 odontoid fracture.

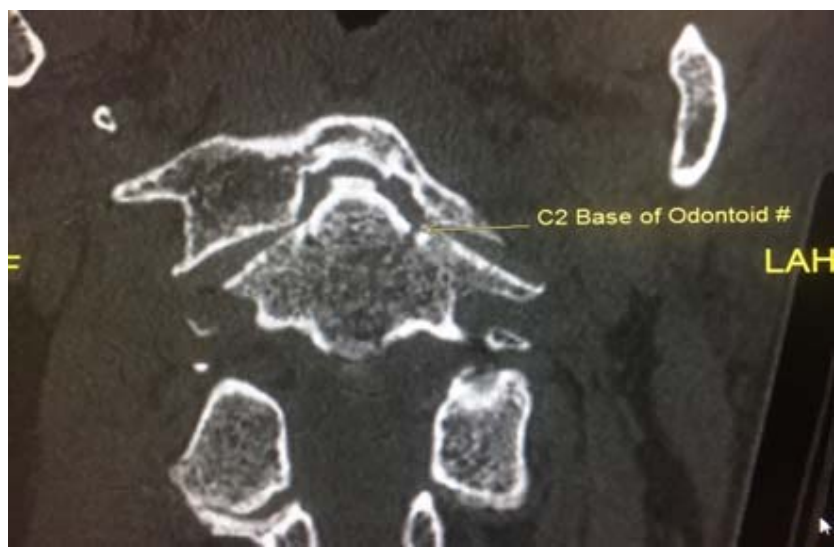

Figure 2. Type 2 odontoid fracture.

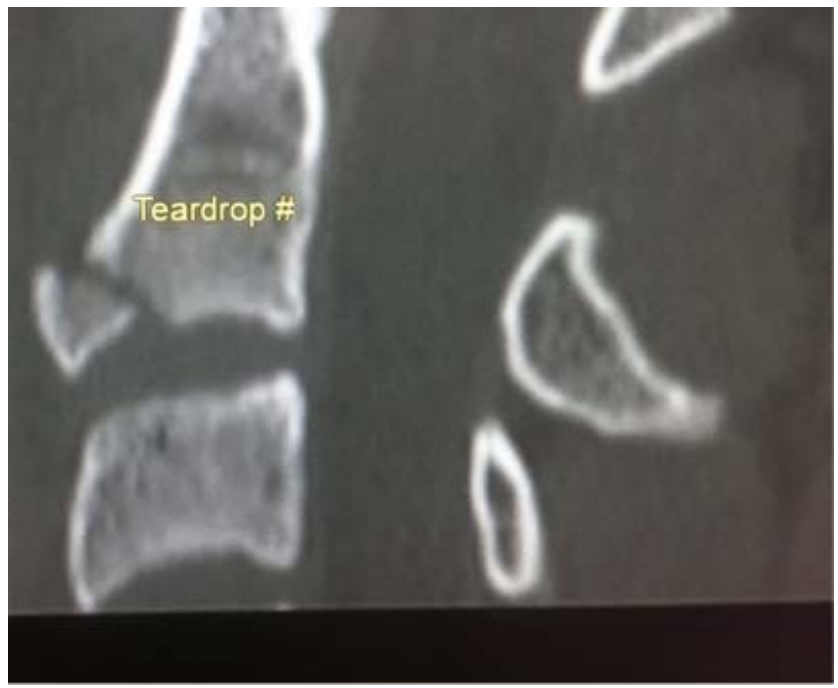

Figure 3. Teardrop fracture.

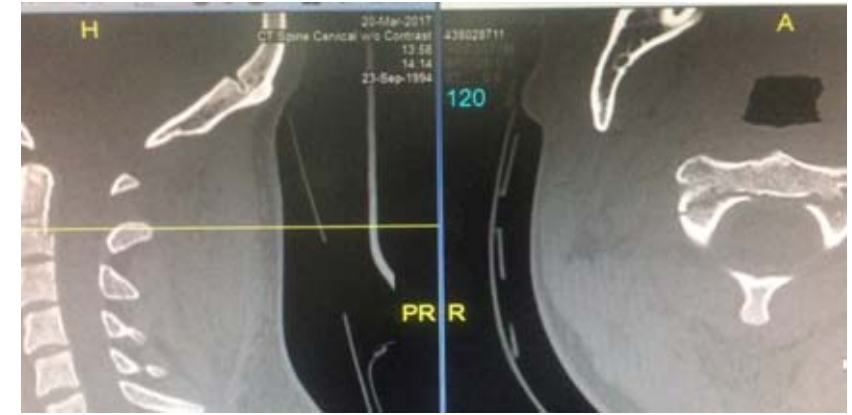

Figure 4. Bilateral pedicles fractures.

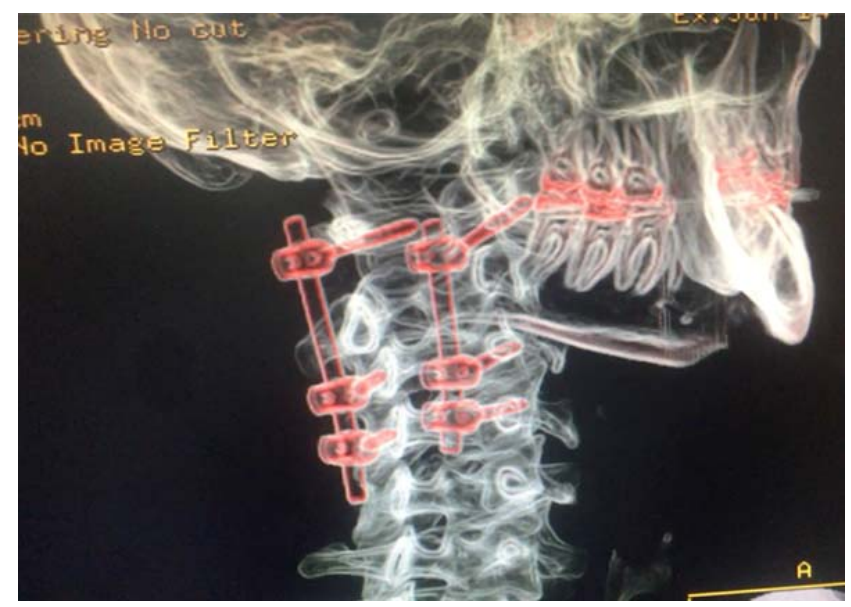

Figure 5. Reformatted image: $\mathrm{C} 1-\mathrm{C} 4$ posterior fixation.

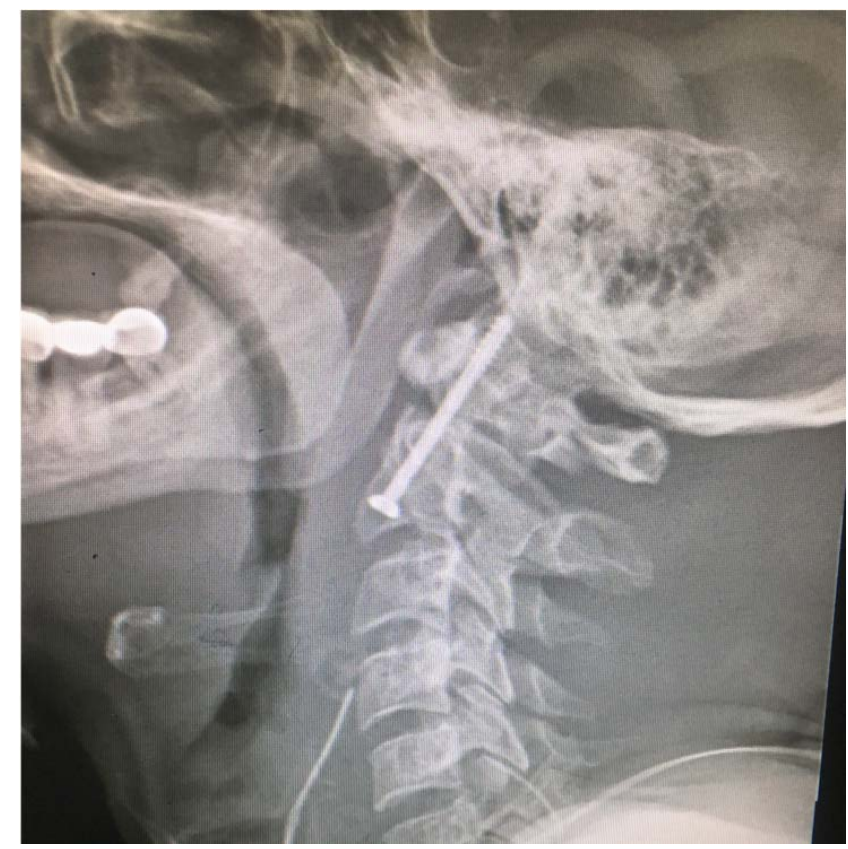

Figure 6. Odontoid process fixation. 
Table 1. Types of C2 fractures.

\begin{tabular}{lr}
\hline Type & No. \\
\hline Odontoid type 2 & 8 \\
Odontoid type 3 & 1 \\
C2 vertebral body & 11 \\
Odontoid type 2, C1 & 3 \\
Odontoid type 2, Hangman & 1 \\
C2-C1 & 1 \\
C2-C3 & 1 \\
\hline
\end{tabular}

dorsal spine fracture. All patients had CT cervical spine scans, and MRI scans were performed in $84.6 \%$ of cases. Ligamentous tears were present in $13.6 \%$ of cases. MRI/CT angiography was arranged for $38.5 \%(10 / 26)$ of cases. We did not identify any patient with vertebral artery injury or thrombosis.

The conservative treatment in the form of a Philadelphia collar was opted in $77 \%$ of patients for 3 months. None of the patients required any cervical traction. Only $23.1 \%(6 / 26)$ of patients needed surgery to fix their unstable fractures. Three patients of odontoid type 2 fractures required anterior odontoid screw insertion. In 1 patient, we failed to insert an odontoid screw. This patient later refused repeat surgery and self-discharged against medical advice. One patient underwent anterior cervical discectomy fusion and fixation, and 4 patients had posterior fusion and fixation. $\mathrm{C} 1-\mathrm{C} 2$ was fused in 1 case, 2 patients had fusion of $\mathrm{C} 1-\mathrm{C} 4$, and 1 patient had fusion of $\mathrm{C} 1-\mathrm{C} 3$. No perioperative complications occurred in any of our cases.

There was a $50 \%$ dropout rate in the follow-up of patients. Thirteen patients had CT cervical spine scans 9 months after discharge. Most of the patients during follow-up complained of neck pain. None of them developed any delayed myelopathy. Overall, we achieved healing of fractures in 9 out of 13 patients. In the conservative management group, nonhealing was observed in 4 out of 13 cases, whereas in the operated group, there was clear evidence of healing on CT scans in all cases. Only 1 patient developed deep surgical site wound infection, but it did not mandate removing his implant. One polytrauma case with $\mathrm{C} 2$ fracture expired due to the variety of his comorbidities and complications, such as septicemia and pulmonary embolism.

\section{DISCUSSION}

Our study is the first study from this region that has exclusively highlighted the epidemiology and morphology of $\mathrm{C} 2$ fractures. This study also showed that life-threatening cervical injuries, such as atlan-
Table 2. Age range of patients.

\begin{tabular}{lc}
\hline Range, $\mathbf{y}$ & No. \\
\hline $0-10$ & 1 \\
$11-20$ & 2 \\
$21-30$ & 9 \\
$31-40$ & 2 \\
$41-50$ & 2 \\
$51-60$ & 5 \\
$61-70$ & 5 \\
\end{tabular}

to-occipital and atlantoaxial dislocation, which are common in the pediatric age-group, are either exceedingly uncommon or do not reach hospitals. Since these injuries cause severe neurological deficits, neurogenic shock, and a high rate of fatalities at the time of the accident, they are seen less commonly in clinical practice. ${ }^{13}$ Dickman et $\mathrm{al}^{14}$ reported a series of 14 such type of patients in which all cases presented with severe neurological deficit, and 11 out of 14 cases subsequently died.

In our series, the cervical spine was involved in $43.5 \%$ of cases, whereas $\mathrm{C} 2$ fractures were involved in $26 \%$. Fifty percent of patients had odontoid process fractures. In many case series, at least onethird of the cases involved the cervical spine. C2 fractures have been reported as the most common type with variable incidence. ${ }^{15}$ Any part of the C2 vertebrae can be affected, but odontoid process fractures have drawn much attention and discussion. ${ }^{16}$ The management of these fractures depends on the age of the patient, fracture stability, ligamentous integrity, and whether the $\mathrm{C} 2$ fracture is isolated or associated with other contiguous or noncontiguous cervical fractures. ${ }^{17}$ Odontoid type 1 and 3 fractures are managed by the Philadelphia collar with a high fusion rate, but controversy prevails regarding the management of type 2 fractures. ${ }^{18}$

Odontoid fractures have some unique aspects that need to be mentioned. First, type 2 fracture is the most common variety in both trauma and fall cases. Second, these fractures are notorious for their nonhealing tendency. Third, the incidence of odontoid fractures is globally increasing in the elderly population. The morphology and bone densities are different in elderly people due to their metabolic diseases and senile osteoporosis. Therefore, this group poses challenges for treating surgeons. An operative versus a conservative approach is an old controversy, but currently, the balance is tipped toward nonoperative measures. ${ }^{18,19}$ Worldwide, several studies have been conducted to learn the 
real outcome of operative treatment of odontoid type 2 fractures in the elderly, but almost all studies have reported the high incidence of mortality and morbidity in this age-group. Therefore, patients over 85 years old are currently not deemed suitable for surgery. ${ }^{20}$ Robinson et al ${ }^{21}$ published a systematic literature review and concluded that odontoid nonunion is not associated with worst clinical outcome and that the complication rate of conservative management is similar to the complication rate of surgical treatment in the elderly.

Nonunion or delayed healing of type 2 fractures has generated active and ongoing discussion regarding ideal management. Nonsurgical means provide up to a $70 \%$ fusion rate, but surgery increases the chance of further healing. ${ }^{22}$ Anterior odontoid screw fixation, the Magerl technique, and posterior C1-C2 screw-rod fixation are some of the commonly used surgical techniques. ${ }^{23}$ Anterior cervical screw fixation is apparently a straightforward procedure but is not free of complications. The Magerl technique is an ideal one but needs a high degree of expertise, whereas posterior $\mathrm{C} 1-\mathrm{C} 2$ fusion severely limits cervical motion. ${ }^{24}$

In our study, the majority of the patients belonged to the younger age-group. Only $8 \%$ of patients were in the age-group of 60years or older. This discrepancy may be due to our geographical location. In Western areas, such as North America and Japan, the elderly population is steeply rising because of their high standard of health care and strong social security system. The Saudi population is comprised mainly of young, healthy, and active people. This region also has a very high incidence of road traffic accidents. ${ }^{25}$ These factors may be an underlying cause of the low incidence of elderly cases in our study. The current international literature is replete with many case series of odontoid fractures in the elderly and their various treatment modalities and outcomes. ${ }^{26}$

Our study shows that the odontoid process is the most commonly fractured part in C2 injury. We did not find even a single case of type 1 fracture, but type 2 fractures, either isolated or combined with $\mathrm{C} 1$ and $\mathrm{C} 3$, were indeed common. The incidence of isolated and associated odontoid fractures of $\mathrm{C} 2$ is $50 \%$ in this study. Type 3 fractures are also the least common variety. ${ }^{26,27}$ There is a widely held belief either that type 2 odontoid fractures do not heal or that union is delayed. Therefore, many surgeons advocate early surgery in these cases. Several studies have addressed this issue and cited a wide range of rates of union and malunion of fractures. Some studies have been conducted to investigate the real cause of this malunion or delayed union. The most prevalent concept is that the blood supply of the odontoid base is either meager or disrupted at the time of injury. ${ }^{28}$ Some studies have performed angiographic studies in cadavers and in live patients but found no convincing evidence that poor blood supply is the real underlying cause of malunion. The whole odontoid process, from the base to the tip, has a profuse blood supply coming from bilateral ascending pharyngeal and vertebral arteries. So the concept of nonunion based on blood supply seems to be erroneous. ${ }^{16,18,19,29}$

The best approach in the initial management of C2 fractures is to do CT cervical spine scans with dedicated images of the craniocervical junction followed by MRI. Its sensitivity and specificity are more than $90 \%$. Today, plain $x$-ray radiography of the cervical spine has a little role to play in the initial management of cervical injuries. ${ }^{30}$ All of our patients had CT cervical spine scans in the axial, sagittal, and coronal planes with subsequent reformation to understand the patho-anatomy of the injured spine. This modality provides an insight regarding bony integrity and the stability of the injured spine. $^{27}$

MRI of the cervical spine was performed in 22/26 cases to discover any unstable fractures. Only 3 patients had partial ligamentous tears, and one of these was a cruciate ligament. ${ }^{7,31}$ This shows that routine MRI for C2 fractures is not mandatory if fractures are clinically and radiologically stable and require subsequent conservative management. However, for academic and medicolegal purposes, this modality is often necessary. This kind of approach can reduce the cost of resource management in poor Third World countries.

$\mathrm{CT} / \mathrm{MRI}$ angiography was performed in a very select number of cases where there was a strong suspicion of ligamentous or vascular injury. A fracture line running through the transverse foramen, a severe facet joint fracture, a facet joint subluxation or dislocation, and the presence of any neurological deficit are some of the strong indications for this investigation. Surprisingly, none of our cases showed any vertebral artery injury or thrombosis. Many studies have reported variable incidences of vertebral artery injury, but our study failed to show any such incidence either because of a 
fewer number of cases or because our cases belonged to only the upper cervical spine, where the vertebral artery is probably less vulnerable..$^{23,32}$

In our case series, none of isolated or associated C2 fractures had any neurological deficit. One patient was paraplegic, but that was because of his concomitant thoracic spine fracture. Several case series have reported different rates of the neurological deficit in upper cervical injuries. ${ }^{20}$ This discrepancy was noticed because other studies included high upper cervical and subaxial injuries, which are usually complicated with neurological deficit. ${ }^{33}$ This subset of injuries was nonexistent in our study for some unknown reason. This study concludes with confidence that $\mathrm{C} 2$ fractures themselves are rarely associated with any kind of neurological deficit.

The real management of $\mathrm{C} 2$ fractures in general and type 2 odontoid process fractures in particular is difficult and controversial task. ${ }^{24,34}$ Our aims were to maintain spine alignment, promote adequate healing, and preserve range of motion. Surgery usually offers good alignment and fixation but severely limits the movements of the cervical spine. $^{35,36}$

Surgery offers the best chance of healing, but implant-related complications are also well known. On the other hand, young patients achieve good healing with hard neck collars, but older patients get good healing at the cost of many potential complications due to their associated comorbidities. Healing, which was our main aim, was best achieved in almost all kinds of $\mathrm{C} 2$ fractures except type 2 odontoid. The commonly cited reason for delayed healing is morphology of bone at the base of dense, as it is more cortical than cancellous. The reported union rate for type 2 fractures treated with immobilization either in a halo vest or in a sternal occipital mandibular immobilizer (SOMI) brace was $76 \%$. Currently, anterior screw fixation, either single or double, has been a popular surgical treatment. The posterior procedures provide strong fixation and good bone healing, but the sacrifice of atlanto-axial rotary motion is inevitable. Surgery seems more plausible, but even operation results in $33 \%$ nonunion. ${ }^{37}$

The current management of $\mathrm{C} 2$ fractures depends on the surgeon's personal judgment, expertise, and available resources, although these are not evidence based, and no universally accepted guidelines are available. $^{34,36,38} \mathrm{We}$ operated those cases who had combined fractures, such as $\mathrm{C} 2-\mathrm{C} 1$ and $\mathrm{C} 2-\mathrm{C} 3$, ligamentous tears, fracture displacement $>5 \mathrm{~mm}$, angulation $>10^{\circ}$, and the presence of neurological deficits. Odontoid fractures with the intact transverse ligament were considered for anterior screw fixation. Direct anterior screw fixation provides immediate spinal stabilization and preserves rotation of $\mathrm{C} 1$ on $\mathrm{C} 2$. Nine months postoperatively, repeat $\mathrm{CT}$ cervical spine scans showed promising healing and satisfactory fusion.

We scheduled regular follow-up for all patients on a 3-month basis to observe neurological status and radiological evidence of healing. Routine plain $\mathrm{x}$-rays of the cervical spine were done on every visit, and neurological examination was done on all attending patients. Nine months after either surgery or accident, CT scans of the cervical spine without contrast were done to check the healing process of the fractures. In spite of all our efforts, only $50 \%$ of patients were available for follow-up, in which CT cervical spine scans were done. Status of healing was assessed with the help of a neuroradiologist. Complete healing was noticed in all cases who were treated surgically, but in the conservative group, few patient fractures did not heal at all. These patients were kept on as-needed pain medication and a neck collar. During follow-up, we did not see any patient with worsening neurological deficits in either the conservative or the surgically treated groups. Neck pain was a persistent complaint in many patients, but no one had a compromise of neck movements. The cervical collar was removed, and patients resumed their normal daily life activities and had good radiological healing.

We observed from this study that those who underwent surgical intervention showed the best immediate and late outcomes. Because of the very low number of these patients, we were unable to give statistically significant results.

Our study is not an ideal one, and it has several limitations. First, our data are scarce regarding showing the incidence of odontoid fractures in elderly. Our findings regarding types of fractures may have some observer bias, as odontoid fractures have been classified on a radiological basis. We did not perform regular angiography of the neck, which is a gold standard; therefore, our findings on vertebral artery damage may not be conclusive and convincing. We did not randomize our cases; hence, our inclination toward conservative management may be deemed biased. We were not able to compare SOMI braces and halo vests with Phila- 
delphia collars. Due to poor follow-up of the patients, we could not gauge any delayed neurological deficit in the form of myelopathy. We did notice significant early healing, but it is too early to comment about good healing. In spite of all these limitations, we are very confident that this study will provide enough insight and provide benchmarks and milestones in future studies of $\mathrm{C} 2$ fractures.

Moreover, it is recommended that multicenter randomized controlled studies be launched in the near future to find clear answers regarding the controversial issues on the subject. All young patients with stable fractures should receive an adequate conservative trial before embarking on surgery.

\section{CONCLUSIONS}

We can safely conclude that $\mathrm{C} 2$ injuries and odontoid fractures are common entities in young trauma patients in Saudi Arabia. These injuries are usually stable and can be managed conservatively. Only those patients who have neurological deficit, ligamentous tears, significant displacement, or angulation of fractures should be subjected to surgical procedures.

\section{REFERENCES}

1. Offiah CE, Day E. The craniocervical junction: embryology, anatomy, biomechanics and imaging in blunt trauma. Insights Imaging. 2017;8(1):29-47.

2. Lopez AJ, Scheer JK, Leibl KE, Smith ZA, Dlouhy BJ, Dahdaleh NS. Anatomy and biomechanics of the craniovertebral junction. Neurosurg Focus. 2015;38(4):E2.

3. Swartz EE, Floyd RT, Cendoma M. Cervical spine functional anatomy and the biomechanics of injury due to compressive loading. J Athl Train. 2005;40(3):155-161.

4. Vaccaro AR, Hulbert RJ, Patel AA, et al. The subaxial cervical spine injury classification system: a novel approach to recognize the importance of morphology, neurology, and integrity of the disco-ligamentous complex. Spine (Phila $\mathrm{Pa}$ 1976). 2007;;32(21):2365-2374.

5. Joaquim AF, Patel AA. Craniocervical traumatic injuries: evaluation and surgical decision making. Global Spine J. 2011;1(1):37-42.

6. Kasliwal MK, Fontes RB, Traynelis VC. Occipitocervical dissociation-incidence, evaluation, and treatment. Curr Rev Musculoskelet Med. 2016;9(3):247-254.

7. Gornet ME, Kelly MP. Fractures of the axis: a review of pediatric, adult, and geriatric injuries. Curr Rev Musculoskelet Med. 2016;9(4):505-512.

8. Jackson RS, Banit DM, Rhyne AL, Darden BV. Upper cervical spine injuries. J Am Acad Orthop Surg. 2002;10(4):271280 .

9. Schleicher P, Pingel A, Kandziora F. Safe management of acute cervical spine injuries. EFORT Open Rev. 2018;3(5):347357.

10. Scholz M, Kandziora F, Kobbe P, Matschke S, Schleicher P, Josten C. Treatment of axis ring fractures: recommendations of the Spine Section of the German Society for Orthopaedics and Trauma (DGOU). Global Spine J. 2018;8(suppl 2):18S-24S.

11. Hadley MN, Browner C, Sonntag VK. Axis fractures: a comprehensive review of management and treatment in 107 cases. Neurosurgery. 1985;17(2):281-290.

12. Shetty A, Kini AR, Prabhu J. Odontoid fractures: a retrospective analysis of 53 cases. Indian J Orthop. 2009;43:352360.

13. Labler L, Eid K, Platz A, Trentz O, Kossmann T. Atlanto-occipital dislocation: four case reports of survival in adults and review of the literature. Eur Spine J. 2004;13(2):172180.

14. Dickman CA, Papadopoulos SM, Sonntag VK, Spetzler RF, Rekate HL, Drabier J. Traumatic occipitoatlantal dislocations. J Spinal Disord. 1993;6(4):300-313.

15. Wang H, Ou L, Zhou Y, et al. Traumatic upper cervical spinal fractures in teaching hospitals of China over 13 years: a retrospective observational study. Medicine (Baltimore). 2016;95(43):e5205.

16. Tadros A, Sharon M, Craig K, Krantz W. Characteristics and management of emergency department patients presenting with $\mathrm{C} 2$ cervical spine fractures. Biomed Res Int. 2019;2019:4301051.

17. Joaquim AF, Ghizoni E, Tedeschi H, et al. Upper cervical injuries - a rational approach to guide surgical management. J Spinal Cord Med. 2014;37(2):139-151.

18. Robinson AL, Olerud C, Robinson Y. Epidemiology of C2 fractures in the 21st century: A National Registry cohort study of 6,370 Patients from 1997 to 2014. Adv Orthop. 2017;2017:6516893.

19. Govender S, Maharaj JF, Haffajee MR. Fractures of the odontoid process. J Bone Joint Surg Br. 2000;82(8):1143-1147.

20. Gonschorek O, Vordemvenne T, Blattert T, Katscher S, Schnake KJ, Spine Section of the German Society for Orthopaedics and Trauma. Treatment of odontoid fractures: recommendations of the Spine Section of the German Society for Orthopaedics and Trauma (DGOU). Global Spine $J$. 2018;8(suppl 2):12S-17S.

21. Robinson Y, Robinson AL, Olerud C. Systematic review on surgical and nonsurgical treatment of type II odontoid fractures in the elderly. Biomed Res Int. 2014;2014:231948.

22. Sawarkar DP, Singh PK, Siddique SA, et al. Surgical management of odontoid fractures at level one trauma center: a single-center series of 142 cases. Neurol India. 2015;63:40-48.

23. Rao G, Apfelbaum RI. Odontoid screw fixation for fresh and remote fractures. Neurol India. 2005;53(4):416-423.

24. Cutler HS, Guzman JZ, Lee NJ, et al. Short-term complications of anterior fixation of odontoid fractures. Global Spine J. 2018;8(1):47-56.

25. Mansuri FA, Al-Zalabani AH, Zalat MM, Qabshawi RI. Road safety and road traffic accidents in Saudi Arabia. A systematic review of existing evidence. Saudi Med J. 2015;36(4):418-424.

26. Robinson AL, Möller A, Robinson Y, Olerud C. C2 Fracture subtypes, incidence, and treatment allocation change 
with age: a retrospective cohort study of 233 consecutive cases. Biomed Res Int. 2017;2017:8321680.

27. Utz M, Khan S, O'Connor D, Meyers S. MDCT and MRI evaluation of cervical spine trauma. Insights Imaging. 2014;5(1):67-75.

28. Althoff B, Goldie IF. The arterial supply of the odontoid process of the axis. Acta Orthop Scand. 1977;48(6):622-629.

29. Haffajee MR. A contribution by the ascending pharyngeal artery to the arterial supply of the odontoid process of the axis vertebra. Clin Anat. 1997;10(1):14-18.

30. Como JJ, Diaz JJ, Dunham CM, et al. Practice management guidelines for identification of cervical spine injuries following trauma: update from the Eastern Association for the Surgery of Trauma Practice Management Guidelines Committee. J Trauma. 2009;67(3):651-659.

31. Boughton OR, Bernard J, Szarko M. Odontoid process fractures: the role of the ligaments in maintaining stability. A biomechanical, cadaveric study. SICOT J. 2015;15(1):11.

32. Jang JW, Lee JK, Hur H, Seo BR, Lee JH, Kim SH. Vertebral artery injury after cervical spine trauma: a prospective study using computed tomographic angiography. Surg Neurol Int. 2011;2:39.

33. Fujimura Y, Nishi Y, Chiba K, Kobayashi K. Prognosis of neurological deficits associated with upper cervical spine injuries. Paraplegia. 1995;33(4):195-202.

34. Julien TD, Frankel B, Traynelis VC, Ryken TC. Evidence-based analysis of odontoid fracture management. Neurosurg Focus. 2000;8(6):e1.

35. Yuan S, Wei B, Tian Y, et al. The comparison of clinical outcome of fresh type II odontoid fracture treatment between anterior cannulated screws fixation and posterior instrumentation of C1-2 without fusion: a retrospective cohort study. $J$ Orthop Surg Res. 2018;13(1):3. doi: 10.1186/s13018-017-0702-0

36. Nourbakhsh A, Shi R, Vannemreddy P, Nanda A.
Operative versus nonoperative management of acute odontoid Type II fractures: a meta-analysis. $J$ Neurosurg Spine. 2009;11(6):651-658.

37. Joaquim AF, Patel AA. Surgical treatment of Type II odontoid fractures: anterior odontoid screw fixation or posterior cervical instrumented fusion? Neurosurg Focus. 2015 38(4):E11.

38. Shears E, Armitstead CP. Surgical versus conservative management for odontoid fractures. Cochrane Database Syst Rev. 2008;4:CD005078.

Disclosures and COI: The authors received no funding for this study and report no conflicts of interest.

This work was presented at the Third Saudi Spine Society Annual Conference (November 16-18, 2019), Dammam, Kingdom of Saudi Arabia.

Corresponding Author: Ahmed Bakhsh, MBBS, MS, Prince Mohammed Bin Abdulaziz Hospital, Riyadh, Kingdom of Saudi Arabia. Phone: 00966532981744; Email: ahmedbakhsh@ gmail.com.

Published 22 January 2021

This manuscript is generously published free of charge by ISASS, the International Society for the Advancement of Spine Surgery. Copyright @ 2020 ISASS. To see more or order reprints or permissions, see http://ijssurgery.com. 